\title{
CONFUSIÓN LINGÜÍSTICA Y GENERACIÓN NARRATIVA (CULTOS E ILETRADOS)
}

\author{
J. IGNACIO DÍEZ FERNÁNDEZ \\ Universidad Complutense
}

Algunas veces la inexperiencia de la
gente inculta asume muchos compromi-
sos y cree saber cosas que no sabe
(Flavio Vegecio Renato, Compendio de
técnica militar).

Es más que probable que en el año 2005, año de celebraciones cervantinas y quijotescas, la ya pesada carga de interpretaciones simbólicas y metafóricas que arrastra el Quijote se haya visto considerablemente aumentada. La novela parecería encerrar una gran variedad de «lecturas» y este hecho, que podría interpretarse como un signo de la riqueza del texto - de esa «ambigüedad» nutricia de las grandes obras literarias -, quizá se ha convertido en una de las características que el Quijote ha «recibido» y que lo distingue de cualquier otra novela o de cualquier otro texto literario. Tengo la sensación de que quienes se adentran en ese atrayente piélago de las interpretaciones y lecturas del Quijote estuvieran poseídos tanto por la pasión de desvelar una clave misteriosa - que estaba, sin embargo, en la mente de Cervantes y en la de los primeros lectores, pero que, luego, se ha perdido hasta que el brillante exégeta la ha recuperado-, como por la necesidad imperiosísima de dar una 
visión original del sentido de la novela. Así, el Quijote ha podido leerse como si tratara de cualquier asunto imaginable, como enciclopedia de los saberes del pasado (y, por supuesto, también de la España de Cervantes), incluso como arúspice, pues, en cierto modo, la novela es la biblia de algunos laicos. Naturalmente, y por el mismo motivo, Cervantes se ha convertido en el ejemplo de los sabios, en el lector que todo lo ha leído, en el más astuto encofrador de mensajes, en el razonador más racional, en el adelantado de su tiempo, etc. A mí, sin embargo, frente a este panorama en gran parte aterrador (por su magnitud y sus consecuencias) lo que me interesa es sólo insistir en una obviedad: el Quijote es una narración (lo que desde hace unos doscientos años se llama novela, aunque no recibiera ese nombre en la época de Cervantes) de un extraordinario interés; es una novela divertida, cuyos personajes quizá representen el pasado o el futuro, o encarnen el ideal o la realidad, o sean la imagen de la lucha o de la conformidad, o representen - ¡nada menos! - que el ser de los españoles, aunque sin duda son personajes que, como en toda narración, se nos aparecen como partes de una historia.

Uno de los hilos que forman esa historia es la incomunicación o, al menos, una consideración de los problemas que la comunicación humana puede deparar. A don Quijote no le entiende todo el mundo, pues habla una lengua cargada de arcaísmos que, además, imita la compleja expresión de la prosa literaria que pavimenta los libros de caballerías. Pero esa falta de comprensión también proviene del extraño mundo que habita don Quijote, próximo y distinto del mundo que la narración quiere pintar como real: el caballero ve, oye, siente, piensa y se expresa de una manera que a los demás les resulta en gran parte o totalmente incomprensible ${ }^{1}$.

Del vasto tema de la comunicación quiero seleccionar un aspecto: el que provoca la confusión lingüística en algunos pasajes de las obras cervantinas, y analizar cómo Cervantes la usa para desarrollar o generar su narración. Desde luego, no pretendo poner una suerte de primera piedra para hacer del Quijote (o de la producción cervantina) una gran metáfora de la incomunicación, o para explicar que don Quijote es un héroe aislado e incomprendido o que Cervantes vuelca el rechazo que ha sentido en la sociedad de su tiempo (por posible converso, por pobre, por inteligente, por sensible, por supuesto homosexual, por culto, etc.) al dar una imagen metafórica del existir.

A menudo en el Quijote la confusión lingüística se apoya en la ignorancia de los emisores o receptores, que confunden expresiones que sólo han escuchado y que tratan de embutir en su discurso. Es lo que le ocurre a Sancho con cierta frecuencia. Así, por ejemplo, en una de esas ocasiones en las que

\footnotetext{
${ }^{1}$ Véase el capítulo 4 de mi libro Tres discursos de mujeres. (Poética y hermenéutica
} cervantinas), Madrid, Centro de Estudios Cervantinos, 2004. 
Sancho enhebra su retahíla de refranes, don Quijote se desespera: «¿Adónde vas a parar, Sancho, que seas maldito? [...] Que cuando comienzas a ensartar refranes y cuentos no te puede esperar sino el mesmo Judas que te lleve. Dime, animal, ¿qué sabes tú de clavos, ni de rodajas, ni de otra cosa ninguna?»(II, 19)². La destemplanza de don Quijote hace que Sancho se sienta incomprendido («iOh! Pues si no me entienden [...] no es maravilla que mis sentencias sean tenidas por disparates»), pero no por ello deja de manifestar una autosuficiencia que lo aproxima paradójicamente a don Quijote, por más que sus sistemas expresivos estén tan alejados: «Pero no importa: yo me entiendo, y sé que no he dicho muchas necedades en lo que he dicho, sino que vuesa merced, señor mío, siempre es friscal de mis dichos, y aun de mis hechos». La confusión de fiscal por friscal no impide, en esta circunstancia, la recta comunicación, pero el acalorado don Quijote no está dispuesto a dejar pasar la ocasión y corrige a su escudero y le desea, muy significativamente, «que Dios te confunda»: «Fiscal has de decir [...], que no friscal, prevaricador del buen lenguaje». El coloquio continúa con algunas consideraciones sobre quién debe hablar correctamente («el lenguaje puro, el propio, el elegante y claro, está en los discretos cortesanos», afirma el licenciado) que quizá indiquen el ideal expresivo de Cervantes, aunque, de modo más directo, sirven para oponer, primero en el nivel lingüístico y luego en el de la pericia en el manejo de la espada, la «naturaleza» frente al arte. Lo que podría parecer una gracia más o una insistencia en el retrato de Sancho alcanza una función narrativa clara.

Antes de la tercera salida, cuando Sancho y don Quijote hablan a solas, mientras la sobrina y el ama creen ayudar a impedir la salida de su señor, el escudero comienza su parlamento cometiendo un error expresivo que le corrige el master: no hay que confundir reducida con relucida (II, 7). Sancho le solicita entonces que mantenga la comprensión por encima de la corrección:

Una o dos veces - respondió Sancho-, si mal no me acuerdo, he suplicado a vuesa merced que no me emiende los vocablos, si es que entiende lo que quiero decir en ellos, y que cuando no los entienda diga: «Sancho, o diablo, no te entiendo»; y si yo no me declarare, entonces podrá emendarme, que soy tan fócil...

La confusión de dócil por fócil inicia el engarzado de algunas meteduras de pata expresivas que, una vez más, tienen una función narrativa: aquí son el comienzo de la conversación de amo y señor antes de la última salida. El narrador parece perder su tiempo en diversiones e insistencias que, sin

2 M. de Cervantes, Don Quijote de la Mancha, edición del Instituto Cervantes dirigida por F. Rico, Barcelona, Instituto Cervantes-Crítica, $1998^{2}$. Todas las citas proceden de esta edición. 
embargo, permiten un comienzo de la narración. Muy significativamente del sentir de Sancho son sus palabras en las que se queja de las intenciones del hidalgo - que parecen ser también las del narrador-: «Apostaré yo - dijo Sancho- que desde el emprincipio me caló y me entendió, sino que quiso turbarme, por oírme decir otras docientas patochadas». Como antes, los errores se asocian con la enumeración de refranes que le sirven a Sancho, en este momento, para pedir que se le asigne un salario, tejiendo un discurso largo y confuso («Decid, Sancho amigo, pasa adelante, que habláis hoy de perlas», «Todo eso es verdad - dijo don Quijote-, pero no sé dónde vas a parar»). Cuando se produce la petición, Sancho ha confundido rata por gata, pero la respuesta de don Quijote, lejos de los malos humores y quejas de otras ocasiones $-\mathrm{y}$ de acuerdo con la paciencia y el alegre temperamento que muestra al comienzo del segundo volumen-, consiste en hacer un juego de palabras («a las veces tan buena suele ser una gata como una rata») que Sancho interpreta de inmediato y se autocorrige con rapidez para, al mismo tiempo, no dejar de insistir en que lo importante es ser comprendido ( $Y$ Ya entiendo - dijo Sancho-: yo apostaré que había de decir rata, y no gata; pero no importa nada, pues vuesa merced me ha entendido»). Sin embargo, las bromas de don Quijote le permiten al hidalgo marcar su superioridad sobre el iletrado, y al lector entrar en una conversación difícil y divertida, comprobar el buen humor de don Quijote y las pasiones de autor y narrador por las cuestiones lingüísticas. Aquí no hay realmente confusión en el sentido más abstracto, sino en el de intercambio de expresiones. Además la comprensión está muy encima de la expresión, como don Quijote manifiesta: «y tan entendido [...], que he penetrado lo último de tus pensamientos y sé al blanco que tiras con las innumerables saetas de tus refranes» (que él también demostrará emplear con maestría, a continuación). Antes de acabar el capítulo 7 de la segunda parte Sancho provocará la admiración de Sansón Carrasco por su forma de hablar, en la que se siguen dando confusiones, como la que detiene el ritmo narrativo para que la voz autorial explique el cambio de revocar un testamento y un codicilo por revolcar a ambos. La confusión le permite a Sansón (y al narrador) definir al criado y, de paso, al señor (aunque por otras razones): «confirmólo por uno de los más solenes mentecatos de nuestros siglos, y dijo entre sí que tales dos locos como amo y mozo no se habrían visto en el mundo». ¿Son asimilables las confusiones de Sancho - por más que testimonien una voluntad expresiva que excede las limitaciones de clase y cultura y por más que indiquen, junto a la evidente y graciosa incultura, un deseo de parangonarse con un culto o, al menos, documenten la costumbre de hablar de oídas - con las locuras de don Quijote? La conclusión sin duda exagera lo que se desprende de una mera confusión lingüística, aunque muestra la importancia que Cervantes les 
concede, tanto para caracterizar al personaje, como para educar al público lector. Quizá, como anotan los editores, junto al vulgarismo haya también un equívoco.

$\mathrm{Al}$ lado de los vulgarismos más o menos equívocos, generalmente ridículos y que provocan la corrección de don Quijote, humorística o no, otra fuente de confusión lingüística, menos habitual y más sutil, es la que procede, en último término, de la lectura o bien la que se apoya en la dilogía. En la novela don Quijote se caracteriza por su voracidad lectora de un género en particular, aunque el expurgo de su biblioteca revela a un lector de más amplios vuelos. Frente a sus más próximos (sobrina, ama y escudero), el hidalgo manchego posee la cultura escrita que los demás ignoran (el caso de la sobrina es más complejo $^{3}$ ). Sin embargo - y por paradójico o recto que pueda resultar - esas lecturas de Alonso Quijano no parecen haberle deparado nada bueno, pues son la causa próxima de su locura. En el conocido episodio de los galeotes (I, 22, «uno de los más acertados y más famosos del Quijote»4) se percibe el peso de la cultura en las decisiones de don Quijote, al tiempo que el caballero parecería lidiar con las confusiones que provoca en él el empleo de la lengua del hampa, tan diferente de la que llena las prensas - especialmente en el caso de los libros de caballerías.

Toda la aventura se basa en una confusión sobre el sentido de la palabra

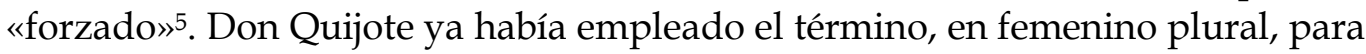
referirse a las mujeres que viajan en el coche que defenderá el vizcaíno (I, 8): «Gente endiablada y descomunal, dejad luego al punto las altas princesas que en ese coche lleváis forzadas; si no, aparejaros a recibir vuestra presta muerte,

\footnotetext{
3 Véase mi trabajo "Mujeres sobre fondo gris en el Quijote: la sobrina y el ama", en F. Rubio (ed.), El Quijote en/clave de mujer/es, Madrid, Universidad Complutense, 2005, pp. 329-352.

4 M. de Riquer, Aproximación al "Qujote», Barcelona, Salvat, 1982, p. 80. Un buen resumen de las interpretaciones del episodio $-\mathrm{y}$ un juicio muy atinado- en M. GarcíaPosada, "El episodio quijotesco de los galeotes: ambigüedad lingüística y significación", Hispanic Review, 49.2 (1981), pp. 195-208. Sobre la "putrefacción del aparato estatal", con un comentario contra lo que sostienen "algunos críticos burgueses", véanse las militantes palabras de L. Osterc, El pensamiento social y politico del "Quijote". Interpretación histórico-materialista, México, UNAM, 1975², pp. 242-250.

5 «En cuanto Sancho ha dicho forzada, surge la aventura, la cual consiste en la palabra", J. Casalduero, Sentido y forma del "Quijote" (1605-1615), Madrid, Ínsula, $1970^{3}$, p. 118. "Formalmente, el texto está vertebrado por un procedimiento de orden semántico: el doble sentido con que se emplea el vocablo "forzado" [...] Ha sido la realidad lingüística, antes que la empírica, la que ha desencadenado la actitud del caballero", M. García-Posada, op. cit., pp. 197-199. También J. F. Martín, "Diálogo y poder en la liberación de los galeotes", Cervantes, 11.2 (1991), pp. 27-34, insiste aunque desde la metodología de Bajtin - en los aspectos lingüísticos de la aventura: "La derrota de las guardas y la posterior derrota de don Quijote no ocurren sólo al nivel de la trama, sino que también ocurren a nivel del discurso [...] Don Quijote se adscribe al poder sirviéndose del ennoblecimiento que le brinda el estilo oratorio", pp. 27 y 31.
} 
por justo castigo de vuestras malas obras». Como es sabido $-\mathrm{y}$ como don Quijote siente-, entre las obligaciones del caballero se halla la defensa del «forzado». Más que detenerme en el grato asunto de la libertad en Cervantes, que tanta tinta ha hecho correr, prefiero insistir en que toda la aventura de don Quijote con los galeotes se inicia gracias a la anfibología del término que permite una interpretación distinta según se tengan en mente las aventuras caballerescas o la lengua del momento. A don Quijote se le explica que la docena de hombres encadenados que contempla son «forzados del rey», "gente forzada del rey»; pero él encuentra una contradicción inasimilable entre la primera parte de la expresión («gente forzada») y la segunda («del rey»). La importancia del sintagma es tal que se escamotea en el título para dar lugar a una perífrasis que, si mantiene el interés del lector para conocer su sentido, también evita adelantar el término clave en el equívoco: «De la libertad que dio don Quijote a muchos desdichados que mal de su grado los llevaban donde no quisieran ir» (la cursiva es mía) ${ }^{6}$.

El episodio se inicia con la visión de los presos y su - cabe pensarprecario andar: «vio que por el camino que llevaba venían hasta doce hombres a pie, ensartados como cuentas en una gran cadena de hierro por los cuellos, y todos con esposas a las manos». Sancho explicará a don Quijote que «esta es cadena de galeotes, gente forzada del rey, que va a las galeras», lo que desencadena la sorpresa de don Quijote: «¿Cómo gente forzada? [...] ¿Es posible que el rey haga fuerza a ninguna gente?». En esta ocasión, es Sancho el que de alguna forma corrige el error de don Quijote, que se ha basado en las palabras de Sancho. El escudero, pues, siente la necesidad de deshacer el equívoco, aunque no lo consigue, por más que no se le pueda culpar del fracaso:

- No digo eso - respondió Sancho-, sino que es gente que por sus delitos va condenada a servir al rey en las galeras de por fuerza.

- En resolución - replicó don Quijote-, como quiera que ello sea, esta gente, aunque los llevan, van de por fuerza, y no de su voluntad.

- Así es - dijo Sancho.

- Pues, desa manera - dijo su amo-, aquí encaja la ejecución de mi oficio: desfacer fuerzas y socorrer y acudir a los miserables.

De nuevo, la superioridad cultural -que en este caso es discursiva meramente - permite a don Quijote reconducir el aserto de Sancho a sus intereses, al obligar a éste a asentir a su visión reductora («en resolución», «como quiera que ello sea») que convierte a los presos en seres carentes de «voluntad» o de libertad. El prisma con el que don Quijote contempla la

${ }^{6} \mathrm{El}$ análisis del título, desde otra perspectiva, en J. F. Martín, op. cit., p. 28. 
realidad no parece admitir - al menos en esta ocasión - esos matices que tan necesarios son, por lo que se simplifican las reglas para, en la mente de un loco (que para otros puede ser la de un idealista), dividir las conductas humanas en libres e impuestas, con olvido de las limitaciones que marcan las leyes. El choque entre el elevado idealismo de los libros de caballerías (en donde no parece que existan los presos, sino simplemente los prisioneros de un rey, un gigante o un caballero) y la dura realidad que representa el lento discurrir de los encadenados convictos (cosificados en «ensartados como cuentas») se resuelve a favor del primero; además, parecería que don Quijote posee las argucias suficientes para imponer su punto de vista sobre el también limitado Sancho. Sin embargo, hasta el escudero sabe distinguir entre la fuerza que puede ejercer un particular (y convertir un apresamiento en un secuestro, por ejemplo) y la que en el ejercicio de la potestas y el imperium despliega, de manera incontestable, el monarca: "Advierta vuestra merced - dijo Sancho- que la justicia, que es el mesmo rey, no hace fuerza ni agravio a semejante gente, sino que los castiga en pena de sus delitos». Tan juicioso comentario, sorprendente en un Sacho iletrado, no admite réplica y don Quijote no lo intenta, quizá porque en ese momento les alcanza la cadena de presos y don Quijote prefiere informarse, «con muy corteses razones», de «la causa o causas porque llevaban aquella gente de aquella manera». A la petición responde, de manera contundente, «una de las guardas de a caballo», aunque no puede decirse que utilice razones, sino asertos: son «galeotes, gente de Su Majestad, que iba a galeras y que no había más que decir, ni él tenía más que saber». Don Quijote no queda satisfecho con esa explicación y quiere averiguar «de cada uno dellos en particular la causa de su desgracia» y de nuevo emplea la fuerza de la persuasión, frente a la imposición de la justicia, del sentido común o de los hechos que manejan los otros. «La otra guarda de a caballo» le anticipa que los presos le darán sus explicaciones porque les encanta «hacer y decir bellaquerías».

Se abre así el largo interrogatorio de don Quijote en el que los presos muestran un muy fino (e irónico y divertido para el lector) empleo del eufemismo, que para don Quijote sólo servirá para aumentar la confusión, es decir, para afianzar su idea de que van todos ellos «forzados». Así se ha interpretado con frecuencia, aunque hay que realizar algunas precisiones pues los eufemismos que emplean con tanta maestría los galeotes («enamorado», «músico y cantor», etc.) quedan aclarados siempre tras su uso, para regocijo de los lectores y también para moderar la supuesta confusión de don Quijote. El caballero andante también se sorprende por el empleo de la jerga marginal, aunque pregunta con libertad o se aclaran sin más los significados de palabras y expresiones como «gurapas», «cantar en el ansia», «las acostumbradas», «en 
pompa», «burlarse» con alguien, etc ${ }^{7}$. El coloquio, que provoca la piedad de Sancho hasta el punto de sentirse movido a dar una limosna al alcahuete y hechicero, se explaya al tratar de Ginés de Pasamonte, que es letrado, como don Quijote: el diálogo se remansa en el libro que ha escrito "por estos pulgares» Ginés. Tras el pormenorizado interrogatorio, don Quijote cede a la tentación de un discurso que resume lo que él ha captado y lo que ha decidido hacer. El buen juicio del caballero le permite saber que van culpados, pero, al mismo tiempo, los argumentos de los charlatanes galeotes le han convencido de que ellos podrían haberse librado del castigo si hubieran tenido más ánimo, dinero o más suerte con el juez. No parece adecuado concluir que el interrogatorio no ha aclarado nada a don Quijote porque los «forzados» emplean una lengua que aquél no comprende, ni tampoco que la conversación haya servido para agravar «los términos de la polarización» ${ }^{8}$. Lo que más mueve a don Quijote a actuar es su destino como caballero y la fuerza de sus votos; además, don Quijote cree en el castigo divino y no en el humano. Directamente, pues, más que las críticas a la justicia de su época, don Quijote sigue teniendo como referente el mundo caballeresco en el que no hay leyes, ni jueces, ni castigos legales -al menos no como en la España del siglo XVII - , sino ordalías, torneos, normas palaciegas, un acusado y peculiar sentido del honor y una manifiesta voluntad del rey. Más que un sentido revolucionario de la justicia, o más aún que la posible pertenencia de don Quijote a un grupo anarquista - como los que, andando el tiempo, parirá la Europa de los siglos XIX y XX- que quiere acabar con la «fuerza» del Estado, don Quijote parte de un sentido de la justicia anterior (anterior incluso al ejercicio señorial) o mítico, en el que los delitos de la gente baja no se castigan con las galeras, sino de otra forma o se perdonan magnánimamente. El narrador se distancia, poco después, al reinterpretar lo sucedido como el «disparate [que] había acometido como el de querer darles libertad» ${ }^{9}$. La petición de libertad tropieza con la lógica negativa del «comisario» que, entre cosas, arguye su falta de autoridad y la de don Quijote mismo para dar esa orden. De nuevo se produce un choque, no entre autoridad y libertad, sino entre dos conceptos: entre la autoridad (concepción propia de una sociedad organizada de otro modo, más complejo) y la jerarquía y el honor caballeresco. Sorprendente o casualmente, como en la conversación con Sancho antes de la tercera salida - que ya he comentado-, en las palabras de don Quijote vuelven a asomar los gatos y sus engaños ( $«$ V Vos sois el gato y el rato y

7 Analiza con detenimiento las expresiones equívocas y jergales -entre otras muchas cosas- C. Rodríguez Chicharro, "Aventura de los galeotes (El Quijote, I, 22). Algunos rasgos estilísticos", La palabra y el hombre, 19 (1984), pp. 65-73.

8 J. B. Avalle-Arce, en M. de Cervantes, op. cit., Volumen complementario, p. 62.

9 Otras valoraciones que recoge la propia novela en M. García-Posada, op. cit., pp. 204205. 
el bellaco!»). El sentido común, del que había hecho gala al principio Sancho, reaparece para protegerse de la salida de la Santa Hermandad, pero don Quijote, muy hábilmente, no contradice a su escudero, aunque su misión se encuentra por encima de todo: «Bien está eso - dijo don Quijote-, pero yo sé lo que ahora conviene que se haga». Un nuevo discurso quijotesco se dirige a los galeotes (a los que trata de "señores") para pedirles el «pago» del que no es ingrato. Tras la rebelión violenta de los galeotes contra su libertador, don Quijote parece arrepentirse y dar la razón a Sancho, pero es sólo aparentemente, pues no menciona que fueran presos y que ha ido su comportamiento contra la ley, ni reconoce que él ha atacado los mandatos del rey, sino que su «arrepentimiento» de nuevo pertenece a la órbita ideológica caballeresca, pues ha ayudado a «villanos»:

Siempre, Sancho, lo he oído decir, que el hacer bien a villanos es echar agua en la mar. Si yo hubiera creído lo que me dijiste, yo hubiera escusado esta pesadumbre; pero ya está hecho: paciencia, y escarmentar para desde aquí adelante (I, 23).

Y una vez más Sancho demuestra su perspicacia al no creer en ese falso arrepentimiento («así escarmentará vuestra merced [...] como yo soy turco»). Frente a las preocupaciones sobre el honor caballeresco que atenazan a don Quijote su escudero opone un buen sentido común muy aderezado lingüísticamente:

el retirar no es huir, ni el esperar es cordura, cuando el peligro sobrepuja a la esperanza, y de sabios es guardarse hoy para mañana y no aventurarse todo en un día. Y sepa que, aunque zafio y villano, todavía se me alcanza algo desto que llaman buen gobierno.

Y don Quijote se rinde «sin replicarle más palabra». En Sierra Morena reaparecen, una vez fuera de peligro, las diferencias lingüísticas que separan a amo y criado, con ese continuo tejer narrativo a partir de bromas y confusiones. Así, al encontrarse la maleta vieja y tras repartirse el botín (don Quijote se queda con un «librillo de memoria» y Sancho con dinero y otras pertenencias), don Quijote lee un soneto en el que se menciona a «Fili» y Sancho cree entender que se trata de un hilo, lo que permite la explicación sobre la necesidad de la poesía para el caballero.

Creo evidente que el episodio de los galeotes nace y tiene todo su sentido a partir de una confusión lingüística, la que permite interpretar «forzado» de dos maneras. No me parece, sin embargo, que don Quijote no entienda las explicaciones de los galeotes, por más que éstos empleen su 
peculiar lenguaje eufemístico y jergal. Tampoco creo que en el episodio don Quijote reivindique la libertad como el bien supremo frente a las exigencias legales de castigo a los culpables de los delitos que así determina la ley. Más bien, tanto la confusión como las decisiones de don Quijote se apoyan en su misión caballeresca, ridícula en su choque frontal con la realidad de la España de los Austrias ${ }^{10}$. Como en otras ocasiones, de ese enfrentamiento entre el mundo libresco de don Quijote y el mundo real de los demás personajes de la novela puede emanar un aura de crítica, aunque sea difícil o imposible determinar sus contornos precisos. Don Quijote no se ha dejado enmarañar por las explicaciones de los galeotes, sino, como en sus aventuras, el motor de su sorprendente actuación ha sido su sujeción caballeresca, desde la cual, y para justificar lo que viene después, suelta esas posibles críticas a la justicia, una justicia del todo incomprensible desde el mundo caballeresco. En todo caso, el episodio parte de un equívoco y se instala, interesadamente, en lo literario para llegar a un final doblemente sorprendente: la liberación de los galeotes, contra todo pronóstico (es una auténtica locura: ningún lector podría suponer al comienzo del episodio que don Quijote quisiera y pudiera reducir a las cuatro guardas bien armadas), y el ataque y robo a don Quijote y Sancho (que sirve, una vez más, para hacer aún más grotesco el contraste entre los ideales literarios de la caballería andante y la vida común). La diversión que proporcionan las peculiares expresiones de los galeotes tienen una función similar a la de las meteduras de pata de Sancho, aunque no sirvan ahora para la diversión del caballero, sino para la del lector. Pero lo importante es que ahora como entonces la comprensión no queda mermada hasta el punto de confundir los contenidos.

También en Rinconete y Cortadillo se contraponen dos modos expresivos de difícil comunicación: el del hampa, que precisa todo tipo de explicaciones y que se utiliza como elemento humorístico, y el más elaborado de los dos ingeniosos jóvenes Rincón y Cortado. En esta ocasión no parece que se opongan con tanta nitidez el saber de los letrados y el de los ignorantes, pero lo cierto es que, a pesar de su juventud, los dos pícaros se muestran superiores a la caterva de Monipodio gracias a una superioridad lingüística. Ninguno entiende la lengua del «mozo de la esportilla» que los capta: «No entendemos esa razón, señor galán», «En verdad, señor [...] que así entendemos esos nombres como

\footnotetext{
10 A pesar de las insistencias criticas en la parodia, no siempre se extraen las consecuencias de un hecho decisivo. En su aproximación al alcahuete A. Redondo sí lo hace y estas palabras serian válidas para todo el episodio de los galeotes: "por ser el libro una parodia de las novelas de caballerías, o sea una imitación degradada y hasta invertida de tales relatos, cuya modalidad predilecta es la ironía [...]", "De las terceras al alcahuete del episodio de los galeotes (I, 22)", Otra manera de leer el "Quijote". Historia, tradiciones culturales y literatura, Madrid, Castalia, 19982, p. 348.
} 
volar»11. Ambos reciben un curso acelerado, más completo que el de don Quijote, de los «nombres de los que ellos llaman germanescos o de la germanía»12. Pero Rincón y Cortado, además - y como don Quijote-, se permiten corregir a sus interlocutores cuando éstos - como Sancho- cambian un término por un vulgarismo más o menos personal:

- Pues ¿qué tiene de malo? - replicó el mozo-. ¿No es peor ser hereje o renegado, o matar a su padre y madre, o ser solomico?

- Sodomita querrá decir vuesa merced - respondió Rincón.

- Eso digo - dijo el mozo ${ }^{13}$.

Naturalmente, puede no ser lo mismo equivocarse en dócil que en sodomita. Monipodio, por su parte, que «representaba el más rústico y disforme bárbaro del mundo»14, tiene, al mismo tiempo, y en irónicas palabras de Rincón, un «altísimo y profundísimo ingenio que hemos oído decir» 15 , como se ha demostrado en su presuntuosa e incorrecta declaración que recoge irónicamente el joven:

Daremos luego noticia a esta felicísima y abogada confraternidad, para que por sus almas se les haga ese naufragio o tormenta, o ese adversario que vuesa merced dice, con la solenidad y pompa acostumbrada; si ya no es que se hace mejor con popa y soledad como también apuntó vuesa merced en sus razones ${ }^{16}$.

A pesar de la superioridad de Monipodio, en el mando y en el discurso, sobre los que componen la cofradía, Rinconete deriva, a su vez, su posición más elevada de que él sí sabe leer, como el narrador cuida de consignar cuando llega el momento de leer en el «libro de memoria»17 que Monipodio lleva «en la

11 M. de Cervantes, Novelas ejemplares, ed. J. García López; estudio preliminar J. Blasco, Barcelona, Crítica, 2001, pp. 177 y 178. Todas las citas proceden de esta edición.

12 M. de Cervantes, Novelas ejemplares, op. cit., p. 179.

13 M. de Cervantes, Novelas ejemplares, op. cit., p. 181.

14 M. de Cervantes, Novelas ejemplares, op. cit., p. 184.

15 M. de Cervantes, Novelas ejemplares, op. cit., p. 186.

16 M. de Cervantes, Novelas ejemplares, op. cit., pp. 186-187.

17 «De acuerdo a tan detallada descripción resulta claro que dicho librillo era de un pago y tenor bien distintos al de Cardenio", A. Castillo Gómez, Entre la pluma y la pared. Una historia social de la escritura en los Siglos de Oro, Madrid, Akal, 2006, p. 71. 
capilla de la capa»: «dióselo a Rinconete que leyese, porque él no sabía leer» 18 . La falta de letras no le impide a Monipodio confiar en los beneficios que pueden reportar los papeles escritos, como descubrimos al saber que también porta, además del «libro de memoria», «un papel doblado de la capilla de la capa, donde estaba la lista de los cofrades, y dijo a Rinconete que pusiese allí su nombre y el de Cortadillo; mas porque no había tintero, le dio el papel para que lo llevase, y en el primer boticario los escribiese» 19 .

Resulta interesante que el narrador de Rinconete y Cortadillo se vea precisado, al acabar su relato, de insistir en las cualidades que distancian a los muchachos de la cofradía de Monipodio y que la principal sea la que tiene que ver con leer y escribir y, naturalmente, con un buen entendimiento. No menos revelador es que al menos Rincón (y quizá también Cortado) se juzgue (como ha dejado claro el narrador, quien también lo considera así) superior a los otros ladrones precisamente porque no cae en las confusiones lingüísticas propias de los iletrados. Esa superioridad es «moral»20, pero no sólo ${ }^{21}$. En la conclusión el narrador no puede resistir la tentación de recapitular algunas de las confusiones que más valora, ni puede reprimir su impulso docente para explicar cuál es la forma correcta:

Era Rinconete, aunque muchacho, de muy buen entendimiento, y tenía un buen natural, y como había andado con su padre en el ejercicio de las bulas, sabía algo de buen lenguaje, y dábale gran risa pensar en los vocablos que había oído a Monipodio y a los demás de su compañía y bendita comunidad, y más cuando por decir per moduum sufragii había dicho per modo de naufragio, y que sacaban el estupendo, por decir estipendio, de lo que se garbeaba; y cuando la Cariharta dijo que era Repolido como un marinero de Tarpeya, y un tigre de Ocaña, por decir Hircania, con otras mil impertinencias 22 .

\footnotetext{
18 M. de Cervantes, Novelas ejemplares, op. cit., p. 209.

19 M. de Cervantes, Novelas ejemplares, op. cit., p. 213.

20 J. García López, en M. de Cervantes, Novelas ejemplares, op. cit., p. 181, n. 159.

21 "Sus infulas de gentileshombres, caballeros e hidalgos, lo son verbales, en lo que la palabra tiene de eficacia seductora y convincente para los mismos que la usan [...] Por contradictorio que sea, las palabras pueden a la misma realidad, y por eso ellos ejercen dentro de la novela como lectores entre analfabetos", F. López Estrada, "Apuntes para una interpretación de Rinconete y Cortadillo. Una posible resonancia de la inversión creadora", en J. J. de Bustos Tovar (coord.), Lenguaje, ideología y organización textual en las "Novelas ejemplares". Actas del Coloquio celebrado en la Facultad de Filología de la Universidad Complutense en mayo de 1982, Madrid, Universidad ComplutenseUniversidad de Toulouse-Le Mirail, 1983, p. 67.

22 M. de Cervantes, Novelas ejemplares, op. cit., pp. 214-215.
} 
Confusión lingüistica y generación narrativa (cultos e iletrados)

La conexión con la justicia probablemente no obedece a las razones que desgrana Casalduero 23 , sino al hecho de que los malhechores de poca monta quizá como hoy - pertenecen a los estratos más bajos de la sociedad. La burla del narrador, que se funde con Rincón aquí también, de esa religiosidad elemental de la gente inculta que compone «la infame academia» se completa con un comentario rápido, pero crítico, de la pasividad de la justicia en Sevilla ${ }^{24}$. El final, ambiguo en buena medida a pesar de todo, quizá no permite muchas alegrías morales, aunque sí quedan a salvo las risas que provoca en alguien que sabe leer y escribir la confusión lingüística de los que, pese a su «rusticidad», tienen ciertas ínfulas y quieren, sin éxito, brillar por su pulida expresión.

\footnotetext{
23 "Nada tiene de extraño que Cervantes haya dispuesto el desarrollo de la aventura de la palabra dentro del tema de la justicia. Junto a los filólogos, los letrados son los encargados de interpretar la palabra que crea el poeta. El filólogo se mueve en la Historia, al letrado le está reservada la vida", J. Casalduero, op. cit., p. 118.

24 "Finalmente, exageraba cuán descuidada justicia habían en aquella tan famosa ciudad de Sevilla, pues casi al descubierto vivia en ella gente tan perniciosa y tan contraria a la misma naturaleza", M. de Cervantes, Novelas ejemplares, op. cit., p. 215.
} 